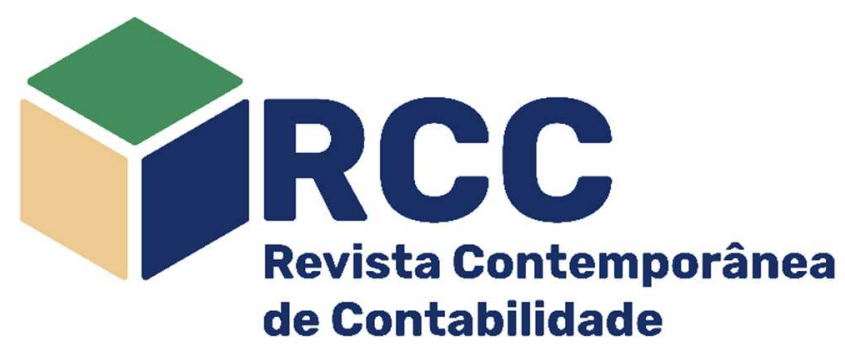

\title{
La investigación sobre contabilidad gubernamental en América Latina. Perspectivas para avanzar
}

\author{
Research on governmental accounting in Latin America. Perspectives forward
}

A pesquisa em contabilidade governamental na América Latina. Perspectivas para avançar

\author{
Michael Andrés Díaz Jiménez \\ Magister en Ciencias Económicas de la \\ Universidad Santo Tomás \\ Profesor tiempo completo en la Universidad Santo Tomás, \\ Bogotá, Colombia \\ michaeldiazj@usantotomas.edu.co \\ https://orcid.org/0000-0001-8227-0714
}

\author{
Carlos Orlando Rico Bonilla \\ Magister en Contabilidad y Finanzas de la Universidad Nacional de \\ Colombia \\ Profesor tiempo completo en la Universidad Santo Tomás \\ carlosricob@usantotomas.edu.co \\ https://orcid.org/0000-0002-0060-0431 (B)
}

Endereço do contato principal para correspondência* Carrera 78 \# 11c-21, Código Postal: 110821, Bogotá, Colombia

\begin{abstract}
Resumen
El objetivo del estudio es establecer algunas perspectivas para avanzar en el desarrollo de la investigación sobre contabilidad gubernamental en América Latina, tomando como referencia un análisis crítico de la producción científica del periodo 2000 - 2018. En este sentido, a partir de la revisión de publicaciones académicas especializadas asociadas a las áreas de gestión y contabilidad se determinó un conjunto de 260 artículos en los que se examinaron parámetros bibliográficos y de contenido como la metodología utilizada, los ámbitos temporales, geográficos y organizacionales abordados, las áreas temáticas tratadas, entre otros. En general, se encontró que, aproximadamente, el $45 \%$ de los documentos examinados se enfocó en la discusión de asuntos normativos sobre las prácticas contables y presupuestales y su convergencia con estándares internacionales. Por tanto, las perspectivas para avanzar se podrían orientar a tópicos como la utilidad de la información financiera (reconocimiento y valoración de bienes públicos e intangibles) y no financiera (aspectos sociales y ambientales), sustentados en alcances teóricos, temporales y geográficos más amplios, una mayor evidencia empírica y una mejor comprensión de la naturaleza y el objeto de diversas organizaciones como los entes fiscalizadores, las universidades, los hospitales y las empresas estatales.

Palabras clave: América Latina; Contabilidad gubernamental; Investigación contable
\end{abstract}

\begin{abstract}
The study's objective is to establish some perspectives to advance in the development of research on government accounting in Latin America, taking as a reference a critical analysis of scientific production from the period 2000 - 2018. In this sense, from the review of specialized academic publications associated with the field of management and accounting determined a set of 260 articles in which bibliographic and content parameters such as the methodology used, the temporal, geographical and organizational areas addressed, the subject areas treated, among others, were examined. Overall, it was found that approximately $45 \%$ of the documents examined focused on the discussion of regulatory issues regarding accounting and budgeting practices and their convergence with international standards. Therefore, the perspectives for progress could be oriented to topics such as the usefulness of financial information (recognition and valuation of heritage assets and intangibles) and non-financial information (social and environmental aspects), supported by broader theorists, temporal and geographical scopes, a greater empirical evidence and a better understanding of the nature and purpose of various organizations such as audit bodies, universities, hospitals and state companies.
\end{abstract}

Keywords: Latin America; Governmental accounting; Accounting research 


\section{Resumo}

O objetivo do estudo é estabelecer algumas perspectivas para avançar no desenvolvimento de pesquisas em contabilidade governamental na América Latina, tomando como referência uma análise crítica da produção científica do período de 2000 a 2018. Nesse sentido, a partir da revisão de as publicações acadêmicas especializadas as áreas de gestão e contabilidade foi determinado um conjunto de 260 artigos nos quais foram examinados parâmetros bibliográficos e de conteúdo, como a metodologia utilizada, as áreas temporal, geográfica e organizacional abordadas, as áreas temáticas tratadas, entre outras. De maneira geral, verificouse que aproximadamente $45 \%$ dos documentos examinados se concentravam na discussão de questões regulatórias relacionadas às práticas contábeis e orçamentárias e sua convergência com os padrões internacionais. Portanto, as perspectivas de progresso poderiam ser orientadas para tópicos como a utilidade das informações financeiras (reconhecimento e valorização de ativos públicos e intangíveis) e informações não financeiras (aspectos sociais e ambientais), apoiadas em escopos teóricos, temporais e geográficos mais amplos, maior evidência empírica e uma melhor compreensão da natureza e finalidade de várias organizações, como entidades fiscalizadoras, universidades, hospitais e empresas estatais.

Palavras-chave: América Latina; Contabilidade governamental; Pesquisa contábil

\section{Introducción}

Desde la historia y la teoría se comprende que la institucionalidad estatal desempeña diferentes roles respecto de la contabilidad, no se trata sólo de sus estados financieros, que de por sí son particulares, además, hay que tener en cuenta la acción del gobierno como un agente económico que recauda impuestos para contratar bienes y servicios dirigidos a lograr metas sociales. Por otra parte, es necesario entender su particular naturaleza como una "macro organización" que determina las reglas formales sobre las que los demás agentes de la economía se desenvuelven en ella, por tanto, hay una función de supervisión que define a la regulación contable (Sunder, 1997; Nikitin, 2001).

Así mismo, desde la óptica de las prácticas profesionales, la contabilidad gubernamental es un área con bastante campo de actuación en el marco de las políticas públicas y las potenciales contribuciones al desarrollo del bienestar social y comunitario. Más cuando actualmente, a nivel global, se subrayan aspectos como los sistemas integrados de información, los estándares internacionales para el sector público, el egovernment, los esquemas de rendición de cuentas y la responsabilidad social del gobierno abierto como elementos clave para el fortalecimiento de los estados (Trigo y Álvarez, 2017; Bergmann, Fuchs y Schuler, 2019).

En este sentido, el objetivo del presente estudio es establecer algunas perspectivas para avanzar en el desarrollo de la investigación sobre contabilidad gubernamental en América Latina. Esto considerando que, la producción científica es un elemento que vale la pena examinar, en la medida en que se constituye en un reflejo de la problemática interacción entre la disciplina de la contabilidad y el gobierno, y, además, en un instrumento sobre el cual sugerir algunas propuestas teóricas, normativas y técnicas relacionadas a la gestión y las finanzas públicas.

Por tanto, en términos metodológicos, se parte de la revisión crítica de publicaciones académicas asociadas a las áreas de gestión y contabilidad, en las cuales se determinó un conjunto de 260 artículos sobre los que se examinaron parámetros bibliográficos y de contenido como la metodología utilizada, los ámbitos temporales, geográficos y organizacionales abordados, las áreas temáticas tratadas, entre otros. Todos los textos se refieren a la región, que a pesar de estar conformada por naciones con una herencia continentaleuropea común y una relativa similitud institucional pocas veces es definida como un área geográfica integrada objeto de estudio, óptica con la cual espera contribuir esta investigación.

La delimitación temporal 2000 - 2018 es definida teniendo en cuenta que, en primer lugar, en esta época en la mayoría de los países latinoamericanos se han venido apreciando los resultados de importantes políticas públicas asociadas, precisamente, a una participación gubernamental más focalizada en la economía que el sólo proceso de financiación estatal, esto como parte también de la implementación de reformas administrativas como el New Public Management (NPM) y la armonización de los sistemas contables públicos con referentes internacionales (Cavanagh y Fernández, 2015; Rico y Díaz, 2017; OCDE, 2019). Además, en segundo término, se reconoce que es en estas décadas iniciales del siglo XXI cuando la investigación contable de la región ha tenido un mayor crecimiento, medido, por ejemplo, por el número de publicaciones, los investigadores, los equipos de trabajo y las ofertas de posgrados (Saavedra y Saavedra, 2015; Macías, 2018).

Entonces, el texto está estructurado de la siguiente manera: adicional a esta introducción, en la segunda parte se contextualizan algunos cambios en la regulación y las prácticas contables de contabilidad gubernamental en la región, de igual manera, se referencian investigaciones previas sobre este tema. En la tercera se presenta el procedimiento metodológico utilizado para el análisis de la literatura. En la cuarta se comentan los resultados, incluyendo las perspectivas para avanzar. Finalmente, en la quinta sección, se formulan las conclusiones. 


\section{Referencial Teórico}

\subsection{Regulación y prácticas de contabilidad gubernamental en América Latina}

Tradicionalmente, los estados latinoamericanos han prestado mayor atención a los modelos presupuestales y fiscales, dejando al margen los procesos contables. En estos predominaban las bases de caja y era evidente la falta de control y transparencia sobre los recursos públicos. No obstante, con la adopción del citado paradigma de la NPM se ha buscado en las últimas décadas formular y ejecutar cambios en esta regulación, las prácticas, el control y la gestión financiera pública (Brusca, Gómez y Montesinos, 2016; Lima y Lima, 2019).

Actualmente, por ejemplo, son pocas las jurisdicciones que no tratan de aplicar la base de devengo para su contabilidad, intentando convertirla en una herramienta útil para la formulación de la información financiera gubernamental, en donde los hechos económicos se reflejen de la manera más fiel, incluyendo los derechos y las obligaciones presentes, y no se limite el análisis al control de las entradas y las salidas de efectivo (Hauque, 2007; Sánchez y Pincay, 2013; Cavanagh y Fernández, 2015). Esto en el marco de reconocidas propuestas de estandarización a nivel global como el Government Financial Statistical Manual del International Monetary Fund (IMF) (Khan y Mayes, 2009; Banco Mundial, 2015).

Igualmente, varios países de la región han incorporado, de distintos modos, en su regulación contable gubernamental, referentes internacionales como las International Public Sector Accounting Standards (IPSAS) emitidas por la International Federation of Accountants (IFAC) con el objetivo de mejorar la calidad de la información financiera. Perú ha adoptado directamente estos estándares en la presentación de reportes financieros gubernamentales. Brasil, Chile, Panamá y Uruguay las han incorporado indirectamente, mientras, países como Bolivia, Colombia, Ecuador y Paraguay las toman como un punto de referencia para construir su regulación. Argentina, México y Venezuela mantienen sus reglamentos locales (IFAC y CIPFA, 2018).

En este proceso también, aparte de los tradicionales presupuestos de inversión y gastos, se han incorporado tímidamente en los gobiernos herramientas de la contabilidad y el control de gestión como los métodos de costeo de bienes y servicios, la medición del desempeño y el capital intelectual, la evaluación por el cumplimiento de indicadores, el balanced scorecard, entre otros elementos que contribuyen a la administración pública a lograr sus metas misionales con una mayor eficacia y eficiencia en el empleo de los diferentes recursos (Borges y Matias, 2011; Leyton y Gil, 2017; Quintanilla y Díaz, 2019).

Por otra parte, el acelerado uso de las tecnologías de la información y la comunicación ha tenido como consecuencia la implementación de Sistemas Integrados de Información que han motivado importantes transformaciones en la orientación, la estructura y la coordinación de las organizaciones gubernamentales latinoamericanas y su respuesta a las diversas necesidades de los ciudadanos. Esta situación ha requerido que dichas entidades desarrollen acciones innovadoras como la aplicación de modelos de gestión y soluciones en línea, más conocidos como e-government (Muñoz, Rodríguez y Garde, 2014).

Aunque estos instrumentos han afectado positivamente el suministro de bienes y la prestación de servicios gubernamentales es aún bastante lo que queda por perfeccionarse en términos de la infraestructura digital, los marcos legales sobre almacenamiento y seguridad de datos, así como, la cantidad, la claridad, el acceso, entre otros aspectos de la revelación de la información financiera y los procesos de rendición de cuentas en América Latina (Gascó, 2005; Lara, Toledo y Gómez, 2012; Gutiérrez y Católico, 2015).

En este sentido, un desafío adicional que se ha abordado en la región es el fortalecimiento de las labores de control y auditoría gubernamental. Si bien, desde la primera mitad del siglo XX, e incluso antes, se han establecido constitucionalmente Tribunales de Cuentas o Contralorías y, además, se han implementado sofisticados modelos nacionales de fiscalización que en algunos casos incluyen la adopción de estándares internacionales sobre la materia; también es cierto que, es amplia la brecha con las nuevas necesidades de información (confiabilidad de los informes, por ejemplo) y las expectativas sociales sobre la función del proceso auditor y la custodia de los recursos públicos (Azevedo y Lino, 2018; Restrepo, 2018).

En este último punto, tanto en el área de la contabilidad como en el control, un aspecto relevante en la región es el tema de la corrupción de las entidades y los funcionarios gubernamentales. El despilfarro, la manipulación, la malversación y el robo, entre otros delitos y conductas punibles contra la administración pública obstaculizan el crecimiento económico, la gobernabilidad, el respeto a las autoridades y deslegitiman la democracia en cada nación (Laurinho, Días y Mattos, 2017; López, 2018).

A pesar de diversas medidas, que incluyen acuerdos internacionales, leyes, políticas e instituciones nacionales, regulaciones focalizadas y alianzas locales y gobiernos corporativos más sólidos al interior de las administraciones públicas, casos como Odebrecht o Lava Jato imprimen una fuerte sombra de inquietud sobre la idoneidad y el control de las cuentas públicas, y obviamente, sobre las competencias y la ética del personal que las prepara y certifica. La sociedad latinoamericana exige respuestas y liderazgo no sólo de la clase política, también de los profesionales y los académicos contables asociados a esta problemática (Machado, 2017; Sodré, 2017). Teniendo esto en consideración, en seguida se describen algunas investigaciones precedentes sobre el tema. 


\subsection{Revisión de literatura}

La investigación sobre la aplicación de la contabilidad en el ámbito gubernamental ha tenido un significativo avance en sintonía con diferentes regulaciones y prácticas desarrolladas en esta área en diversos entornos. Algunos estudios, como los presentados a continuación, son una representación de esto:

Goddard (2010), por ejemplo, estudia la producción científica en contabilidad gubernamental a nivel internacional, a partir de muestra de 188 documentos extraídos de revistas indexadas entre 2005 y 2007. Encuentra que hay dos grandes tendencias en términos epistemológicos y metodológicos, por una parte, los estudios de origen estadounidense anclados en corrientes funcionalistas y aplicaciones cuantitativas, mientras en el resto del mundo, especialmente, Europa occidental y Australia se observan iniciativas para incorporar análisis alternativos, interpretativos y de corte cualitativo. Sugiere la necesidad de un mayor diálogo y cooperación entre estos bloques a fin de lograr avances concretos en las investigaciones en el marco de un esquema interdisciplinar que valide el objeto de estudio desde múltiples teorías y métodos.

Por su parte, Abu Bakar y Saleh (2011) estudian los incentivos que influyen en la divulgación de información contable en entidades estatales en varios países desarrollados. Para esto elaboran busquedas bibliográficas en bases de datos internacionales; con los artículos hallados definen categórias de análisis tales como: año, país, revista de la publicación, palabras clave, subtemas y tipos de organización estatal. Encuentran que en la literatura, priomordialmente anglosajona, se han reafirmado como los factores clave de un bajo nivel de revelación, las limitaciones financieras asociadas a un alto endeudamiento o la aplicación de gastos públicos ineficientes.

Flórez (2017) presenta un marco conceptual de la producción cientifica sobre Gobierno Corporativo en el ámbito estatal, tomando como base investigaciones publicadas en journals internacionales de Public Administration. Indaga por el número de artículos publicados, el nivel de citación, las metodologías más usadas y los temas abordados en cada país y universidad que contribuye a la tématica señalada. Encuentra una incipiente apropiación del concepto estudiado, especialmente en Australia, Estados Unidos y Reino Unido, en la medida en que se adelantan reformas gubernamentales dirigidas a promover la transparencia y la rendición de cuentas.

Otros estudios se enfocan en examinar la producción académica sobre la contabilidad gubernamental en una jurisdicción particular, por ejemplo, Brusca (2010) lleva a cabo una revisión de estas investigaciones en España. Para esto hace un estudio bibliográfico de las publicaciones para el periodo 1981 - 2010. Resalta entre otros aspectos, los tópicos más discutidos, las metodologías utilizadas, las universidades más influyentes y las revistas de mayor reconocimiento. Además, resalta algunas líneas de investigación prometedoras como la contabilidad nacional, la responsabilidad social de las administraciones públicas y la financiación privada de las infraestructuras y los servicios públicos.

Bajo este mismo enfoque los trabajos de Reis, Slomski, Pereira y Mello (2007) y Souza, Silva y Araújo (2013), evidencian los avances investigativos en la contabilidad gubernamental en Brasil. Mediante estudios bibliográficos observan la producción científica desde diferentes ópticas, por ejemplo, describen las revistas y congresos con mayor número de publicaciones sobre la temática, los autores más destacados, la distribución por género y por región geográfica y los temas más descritos. Sobre esto último, identifican que los tópicos de mayor interés son: el presupuesto público, la transparencia y la aplicación de la Ley de Responsabilidad Fiscal.

En esta misma línea, Amaral, Bolfe, y Vicente (2014) exponen las contribuciones académicas sobre el régimen de contabilidad de competencia aplicada al sector público brasilero entre 2005 y 2012. Los criterios de análisis son: el número de artículos por año, las temáticas, los autores más citados y los tipos de referencias utilizadas (artículos, libros, legislación). Los autores manifiestan que no existe una tendencia clara sobre las líneas de investigación en este campo, a pesar de la importante tendencia global a incorporar elementos propios de la contabilidad empresarial en los procedimientos y prácticas gubernamentales. Llaman la atención sobre la necesidad de desarrollar más estudios, con fuertes bases teóricas y metodológicas.

En este sentido, el presente estudio sigue estas contribuciones de la literatura para lograr un examen de la investigación en la contabilidad gubernamental, tomando como ámbito de alcance lo construido puntualmente en América Latina entre 2000 y 2018 y resaltando la producción investigativa, las tendencias temáticas y las perspectiva para avanzar en diferentes tópicos de estudio, en los términos que se enuncian en seguida.

\section{Procedimiento Metodológico}

\subsection{Fuentes}

En primer lugar, se ha procedido a examinar bases de datos bibliográficas como Clase, Dialnet, Emerald, EBSCO, Esci, Latindex, Scielo, Science Direct, Scopus y Taylor \& Francis en ellas se identificó un conjunto de 56 revistas académicas editadas en 11 países relacionadas a las áreas de gestión y contabilidad. Específicamente, se tuvieron en cuenta las investigaciones sobre contabilidad gubernamental en América 
Latina. Esta información se presenta en el anexo, en el que además se indica para cada publicación el año en que apareció el primer número y desde cual fue posible efectuar la revisión por medios electrónicos.

Las bases fueron elegidas atendiendo a su reconocimiento general en las citadas disciplinas. Una vez identificada una revista (no se limitó su origen a la región por esto se encuentran textos publicados en España y Reino Unido), se elaboraron búsquedas sistemáticas en su portal web con el objeto de seleccionar los artículos correspondientes, esto a partir de las palabras clave: sector público o contabilidad gubernamental y sus conceptos equivalentes en inglés y portugués cuando las publicaciones eran en estos idiomas.

Con cada uno de los textos ya definido y almacenado en una base de datos, se realizó una revisión detallada de contenido, para luego clasificarlo y agruparlo según los parámetros de análisis descritos en el siguiente apartado. Vale la pena mencionar, además, que no se consideraron textos relacionados al recaudo, la liquidación y la reglamentación de los impuestos o los asociados al manejo macroeconómico de los países; tampoco notas editoriales o materiales como reseñas, cartas al editor $u$ otros similares.

Como se aprecia en el citado anexo, la mayoría de las publicaciones tienen su origen en Brasil, lo que demuestra el liderazgo de este país, no sólo en la investigación de esta área, sino en la disciplina contable de la región en general. Esta evidencia se contrasta con lo mencionado por Macías (2018) quien resalta que, en la última década, Brasil ha gestado una tradición académica contable muy sobresaliente gracias a la rigurosidad de las universidades federales en el posicionamiento de sus maestrías y doctorados, los eventos académicos y sus revistas científicas, además, por la exigencia de autoridades locales como el Ministerio de Educación en el seguimiento a la producción académica.

En un segundo lugar está Colombia, con algo menos de la mitad de las revistas que Brasil. Al respecto de esta situación, Castaño (2017) plantea que la investigación contable en este país se ha visto beneficiada principalmente por la pluralidad temática, el interés de las universidades en la formación de nuevos investigadores y en la generación de proyectos interinstitucionales, no obstante, se han evidenciado limitaciones como los escasos incentivos y pocas redes académicas con focos de trabajo concretos. En los demás países se presentó una participación inferior y en Bolivia, Paraguay, Uruguay y las naciones de Centroamérica no se encontraron revistas que abordaran el tópico estudiado.

De los artículos analizados, se observa que las revistas brasileras Ambiente Contábil, RBC - Revista Brasileira de Contabilidade, Revista de Contabilidade e Organizações, Revista Catarinense da Ciência Contábil, y la Revista de Contabilidade da UFBA son las que tienen mayor participación. En el caso de Colombia las revistas más representativas son: Revista Internacional Legis de Contabilidad \& Auditoría, Contaduría Universidad de Antioquia, y Cuadernos de Contabilidad. En Perú se encontraron algunos trabajos, distribuidos entre Quipucamayoc y Contabilidad y Negocios. En los demás países el número de estudios seleccionados fue mínimo.

Del análisis también vale la pena resaltar que, 21 de las revistas estudiadas fueron constituidas antes del año 2000, las publicaciones con más tradición son Contaduría y Administración de la Universidad Nacional Autónoma de México que emitió su primer número en el año 1956, y RBC - Revista Brasileira de Contabilidade que circula desde 1971. Además, entre el 2000 y el 2010 se organizaron 27 revistas, y en la década posterior, 8. Estas cifras indican que buena parte de la literatura contemporánea sobre la contabilidad gubernamental de la región fue consultada, y se reafirma lo señalado anteriormente, que es en estas décadas que la investigación contable ha tenido una mayor expansión en América Latina.

\subsection{Parámetros de análisis}

Considerando la guía de los trabajos previos, se tomaron y almacenaron en una base de datos las siguientes características bibliográficas: Nombre(s) del(os) autor(es), año de publicación, título, revista, volumen (número) y rango de páginas. También se examinó en cada uno los siguientes parámetros de contenido:

- Metodología: Se refiere al procedimiento científico utilizado en el desarrollo del estudio, es decir, si se adoptó principalmente una base cuantitativa o una cualitativa. La primera hace referencia al planteamiento de hipótesis validadas a partir del empleo de herramientas estadísticas y econométricas sobre las que se procesa una serie de datos y variables. En la segunda se busca formular y resolver preguntas considerando la descripción detallada, el desarrollo y la contrastación narrativa de un conjunto de argumentos e ideas particulares.

Modo de análisis: Corresponde a los instrumentos utilizados para lograr el desenvolvimiento de la investigación, son de tipo cuantitativo: las herramientas estadísticas y econométricas, que se fundamentan en la definición de probabilidades y tendencias numéricas en la interrelación entre diferentes variables; y la construcción y análisis de indicadores, es decir, la formulación de unos parámetros de medición y comparación soportados conceptual y analíticamente.

También pueden ser de carácter cualitativo como: la reflexión conceptual, se trata del uso del razonamiento en la evaluación de una teoría o un planteamiento científico o normativo; los estudios de caso, consistentes en la observación y el entendimiento de una situación o evento en una entidad económica específica; la descripción de datos, se refiere a la valoración y los efectos contextuales que indican los cambios en un conjunto de cifras; las revisiones de literatura, presentan un marco de términos y tendencias 
alrededor de una temática a partir de las publicaciones previas sobre esta; y el análisis documental, corresponde al establecimiento de interpretaciones o críticas teniendo en cuenta el examen detallado de material manuscrito.

- Fuentes de información básicas: Describe los insumos materiales principales en los que se soporta la investigación para lograr unas determinadas conclusiones, se han establecido: los Cuestionariosentrevistas-listas de chequeo como elementos fruto de un proceso de recolección de información a partir de los cuales se indaga directamente a los actores relacionados al tema estudiado; estados financieros, es decir, los datos contables y la información financiera emitida por las organizaciones objeto de análisis; las normas y demás reglamentaciones legales.

También se tienen fuentes como los informes presupuestales, corresponde a los reportes asociados a las diferentes proyecciones de ingresos y gastos; informes de auditoría, se trata de los dictámenes elaborados por un revisor o auditor independiente sobre la situación financiera de las entidades; archivosmanuscritos, se refieren a material de corte histórico; otros informes o reportes, información relevante no agrupada en otras categorías, y demás fuentes secundarias que apuntan usualmente a trabajos previos sobre un tema.

- Ámbito temporal: Se refiere a si en la investigación se lleva a cabo un estudio de corte transversal o uno longitudinal. En los primeros, los datos recopilados sugieren la evaluación de información en un momento puntual; mientras que en los segundos se examinan los cambios a lo largo del tiempo extrayendo datos de diferentes periodos. En algunos trabajos no es posible determinar este parámetro y los autores no indican nada al respecto, por lo que se contempla la categoría de no se específica este aspecto.

- Ámbito geográfico: Corresponde a la delimitación jurisdiccional que señalan los estudios, puede ser nacional, referido a un estado en particular; local, es decir relacionado a áreas específicas de una determinada municipalidad, gobernación o estado federal; o continental, contemplando información de un conjunto de naciones. En este sentido, también se tomó nota del país o el conjunto de ellos que se trata en cada investigación.

- Ámbito organizacional: Corresponde a las categorías de orden de la administración pública: gobierno nacional, federal o departamental, municipal, y a algunos grupos de entidades particulares como las empresas estatales, los hospitales, los entes de control y las universidades públicas.

- Áreas temáticas: Se han definido cinco, que se relacionan a los grandes ejes disciplinares sobre los que versan las investigaciones: contabilidad financiera, que se refiere a la información contable para usuarios externos; contabilidad de costos y gestión, que incluye lo concerniente a los informes para usuarios internos; control, que trata los aspectos de revisión, auditoría y disminución de riesgos; y, gestión e información presupuestal, para lo que tiene que ver con la planeación y la prospectiva de las entidades gubernamentales. Por último, se ha fijado una categoría de otros temas, para captar los estudios que no se ajustan a ninguno de los anteriores parámetros.

- Tema principal: Considerando la literatura previa y las tendencias observadas en la acumulación de los datos, para cada área disciplinar se han definido una serie de tópicos que corresponden a las tendencias temáticas y las perspectivas de investigación potenciales (Brusca, 2010). En cuanto a la contabilidad financiera se clasifica información entorno a aspectos como la regulación y la normatividad, la normalización y armonización de prácticas contables, la convergencia con IPSAS, la utilidad de la información, entre otros.

En cuanto a la contabilidad de costos y gestión se especifican elementos como el control de gestión, los sistemas de costos, el costeo basado en actividades y el balanced scorecard. Por otra parte, respecto del control se evidenciaron estudios orientados a tópicos como el control fiscal, el control interno, la regulación del proceso auditor, la manipulación y corrupción y el gobierno corporativo, la responsabilidad social y la rendición de cuentas.

En el área asociada a la gestión presupuestal se perfilan temas como deuda pública, gastos públicos, servicios de salud, transparencia y revelaciones, gestión del conocimiento y el talento humano y la ejecución del presupuesto. Finalmente, en otros aspectos se incluyen temáticas como historia, educación, investigación en contabilidad gubernamental y e-government. A partir de todas estas categorías conceptuales se describe y discute lo siguiente.

\section{Resultados del Análisis}

\subsection{Revisión bibliográfica}

En la gráfica 1 se presenta la evolución en el número de publicaciones por año. Como se puede apreciar hay tres etapas claramente identificables en este aspecto. Entre 2000 y 2005 cuando la cantidad de artículos es pequeña con un máximo de 7 en 2003, posteriormente, de 2006 a 2011 con una tendencia de entre 9 y 15 textos, y finalmente, de 2012 a 2018 donde se muestra una línea más variable que va de los 15 a los 30 documentos. En general, se evidencia una dinámica creciente que indica una mayor preocupación de la comunidad académica contable por profundizar en estos temas, especialmente, en Brasil y Colombia. 
Gráfica 1. Número de artículos publicados sobre contabilidad gubernamental, 2000 - 2018

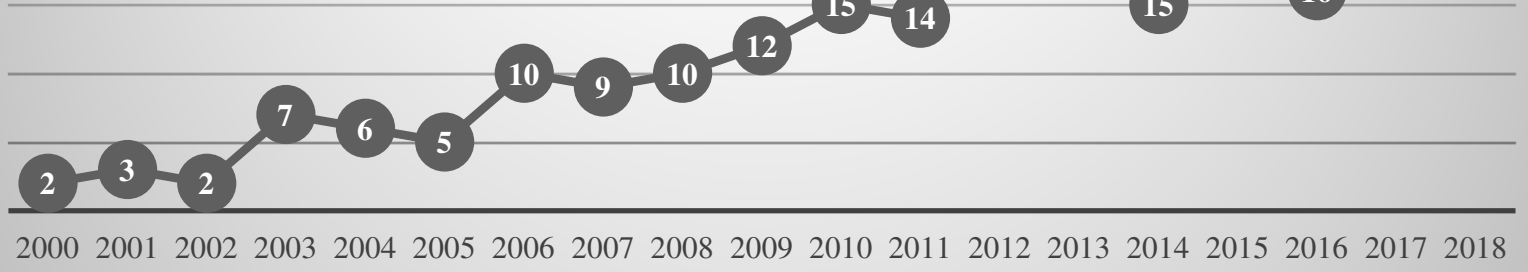

Fuente: Elaboración propia

En este sentido es de señalar que, los 260 artículos revisados fueron escritos por un total de 475 investigadores, algunos incluso de otras regiones del mundo, España y Portugal principalmente. En la tabla 1 se muestra la distribución de los textos de acuerdo con el número de autores, como se puede observar la mayor proporción de los estudios se realizó en equipos, usualmente de entre 2 y 3 investigadores. No obstante, también se distingue una considerable cantidad de investigaciones publicadas por una sola persona.

Tabla 1. Número de artículos según la cantidad de autores, 2000 - 2018

\begin{tabular}{c|c|c}
\hline Número de investigadores por artículo & Número de artículos & Porcentaje de Participación \\
\hline 1 & 62 & $24 \%$ \\
2 & 82 & $32 \%$ \\
3 & 64 & $25 \%$ \\
4 & 42 & $16 \%$ \\
5 & 9 & $3 \%$ \\
6 & 1 & $0,4 \%$ \\
\hline Total & $\mathbf{2 6 0}$ & $\mathbf{1 0 0} \%$ \\
\hline
\end{tabular}

Fuente: Elaboración propia

En el desarrollo del análisis de literatura se identificó que, en correspondencia con el origen de las revistas y el ámbito geográfico estudiado en los diferentes artículos, el mayor número de investigadores también es de origen brasileño. En la tabla 2 se listan las 20 personas que más figuran en las publicaciones, indicando su nacionalidad y filiación institucional. Es de subrayar en cuanto a este último factor, la importante participación de las Universidades de Brasilia, Rio Grande do Norte, São Paulo y Santa Catarina en el caso de Brasil y la Universidad Nacional Mayor de San Marcos en Perú.

Tabla 2. Investigadores con mayor participación en la publicación de artículos, 2000 - 2018

\begin{tabular}{l|l|l|r}
\multicolumn{1}{c|}{ Autores } & \multicolumn{1}{c}{ País } & \multicolumn{1}{c}{ Filiación Institucional } & $\begin{array}{c}\text { Número de } \\
\text { artículos }\end{array}$ \\
\hline $\begin{array}{l}\text { Diana Vaz de Lima } \\
\text { Maurício Côrrea da Silva }\end{array}$ & Brasil & Universidade de Brasília & 11 \\
Orion Augusto Platt Neto & Brasil & Universidade Federal do Rio Grande do Norte & 11 \\
Aneide Oliveira Araujo & Brasil & Universidade Federal de Santa Catarina & 8 \\
Flávio da Cruz & Brasil & Universidade Federal do Rio Grande do Norte & 6 \\
María del Carmen Caba Pérez & Brasil & Universidade Federal de Santa Catarina & 6 \\
André Carlos Busanelli de Aquino & España & Universidad de Almería & 6 \\
Antonio López Hernández & Brasil & Universidade de São Paulo & 5 \\
Jairo Alonso Bautista & España & Universidad de Granada & 5 \\
José Dionísio Gomes da Silva & Colombia & Universidad Santo Tomás & 5 \\
Juan Miñano Lecaros & Brasil & Universidade Federal do Rio Grande do Norte & 5 \\
\hline
\end{tabular}




\begin{tabular}{|c|c|c|c|}
\hline Autores & País & Filiación Institucional & $\begin{array}{l}\text { Número de } \\
\text { artículos }\end{array}$ \\
\hline Alexandre de Freitas Carneiro & Brasil & Universidad Federal de Rondonia & 4 \\
\hline Ernesto Fernando Rodrigues Vicente & Brasil & Universidade Federal de Santa Catarina & 4 \\
\hline Fábia Jaiany Viana de Souza & Brasil & Universidade Federal da Paraíba & 4 \\
\hline Gilmar Ribeiro de Mello & Brasil & Universidade de São Paulo & 4 \\
\hline Jorge Eduardo Scarpin & Brasil & Universidade Regional de Blumenau & 4 \\
\hline Jose Matias Pereira & Brasil & Universidade de Brasília & 4 \\
\hline Julio Flores Konja & Perú & Universidad Nacional Mayor de San Marcos & 4 \\
\hline Valmor Slomski & Brasil & Universidade de São Paulo & 4 \\
\hline Vicente Montesinos Julve & España & Universidad de Valencia & 4 \\
\hline
\end{tabular}

Fuente: Elaboración propia

\subsection{Parámetros de contenido}

En cuanto a los parámetros de contenido se evidenció, como se presenta en la tabla 3, que la mayoría aplicó principalmente una metodología de investigación cualitativa. Esta tendencia va de la mano con el empleo de instrumentos como los análisis documentales y las reflexiones conceptuales básicas. También se observa que hay bastante espacio para las propuestas que utilizan estudios de caso, descripción de datos y revisiones de literatura, como ya lo señalaron Goddard (2010) y Amaral, Bolfe y Vicente (2014) soportados en diferentes enfoques teoricos y metodológicos.

Tabla 3. Distribución de los artículos por la metodología empleada y los modos de análisis

\begin{tabular}{l|r|r}
\hline \multicolumn{1}{c|}{ Metodología/Modo de análisis } & Número de artículos & \multicolumn{1}{c}{ Porcentaje de participación } \\
\hline Análisis documental & 87 & $33 \%$ \\
Reflexión conceptual & 56 & $22 \%$ \\
Estudio de caso & 32 & $12 \%$ \\
Descripción de datos & 17 & $7 \%$ \\
Revisión de literatura & 12 & $5 \%$ \\
\hline Cualitativa & $\mathbf{2 0 4}$ & $\mathbf{7 8 \%}$ \\
\hline Herramientas estadísticas y econométricas & 30 & $12 \%$ \\
Construcción y análisis de indicadores & 26 & $10 \%$ \\
\hline Cuantitativa & $\mathbf{5 6}$ & $\mathbf{2 2} \%$ \\
\hline Total & $\mathbf{2 6 0}$ & $\mathbf{1 0 0 \%}$ \\
\hline
\end{tabular}

Fuente: Elaboración propia

Por su parte, se resalta que los estudios cuantitativos están asociados principalmente al empleo de herramientas estadísticas y econométricas entre las cuales están, por ejemplo, las regresiones lineales, los paneles de datos y los análisis envolventes de estos. Con una proporción más baja, están los trabajos en los que se construyen e interpretan indicadores del tipo grado de comparabilidad, transparencia y revelación de la información, nivel de coincidencia en el empleo de las prácticas contables o presupuestales y variación de distintas razones financieras, que, no obstante, son algunas de las temáticas más prometedoras respecto del tópico de la regulación de la contabilidad gubernamental, como lo indican Souza, Silva y Araújo (2013).

Respecto de las fuentes en las que se sustentan las investigaciones, se nota que la mayor proporción de los trabajos se sustenta en el análisis de las normas y diferentes reglamentaciones, como se puede apreciar en la tabla 4. En un nivel más bajo están los estados financieros que se tomaron como recurso básico, los cuestionarios, entrevistas y listas de chequeo, otros informes y memorias (por ejemplo, reportes de la administración, publicaciones de las entidades públicas, cifras económicas y sociales) y fuentes secundarias (artículos sobre el tema).

El uso de fuentes como los informes presupuestales, los de auditoría y los archivos y fuentes manuscritas es una señal contundente de aspectos en los que todavía hace falta investigar, especialmente, en la comprensión de las prácticas del proceso auditor y la relación entre las entidades gubernamentales y sus agentes fiscalizadores (Tamez y Montesinos, 2011; Silva, Abreu y Couto, 2017). 
Tabla 4. Artículos por fuente empleada para sustentar el análisis

\begin{tabular}{l|r|r}
\multicolumn{1}{c|}{ Fuentes } & Número de artículos & Porcentaje de participación \\
\hline Normas y reglamentaciones & 77 & $30 \%$ \\
Estados financieros & 42 & $16 \%$ \\
Cuestionarios-Entrevistas-Listas de Chequeo & 40 & $15 \%$ \\
Otros informes y memorias & 36 & $14 \%$ \\
Fuentes secundarias & 34 & $13 \%$ \\
Informes presupuestales & 16 & $6 \%$ \\
Informes de auditoría & 9 & $3 \%$ \\
Archivos-manuscritos & 6 & $2 \%$ \\
\hline Total & $\mathbf{2 6 0}$ & $\mathbf{1 0 0 \%}$ \\
\hline
\end{tabular}

Fuente: Elaboración propia

En lo que corresponde al ámbito temporal, gráfica 2, es de señalar que el porcentaje más alto de las publicaciones se concentran en el análisis de corte transversal, en la observación de intervalos de tiempo muy cortos. Otro tanto de los trabajos, no específica este parámetro, esto se da generalmente, en los que emplean modos y de análisis asociados a exámenes documentales y reflexiones conceptuales. El porcentaje de participación más pequeño consiste en evaluaciones de tipo longitudinal; ilustrando otra perspectiva a futuro en la actividad de investigación en la contabilidad gubernamental de la región, a fin de entender procesos contables en largo plazo, como en la literatura previa los ha mencionado Reis, Slomski, Pereira y Mello (2007).

\section{Gráfica 2. Número y porcentaje de investigaciones por ámbito temporal}

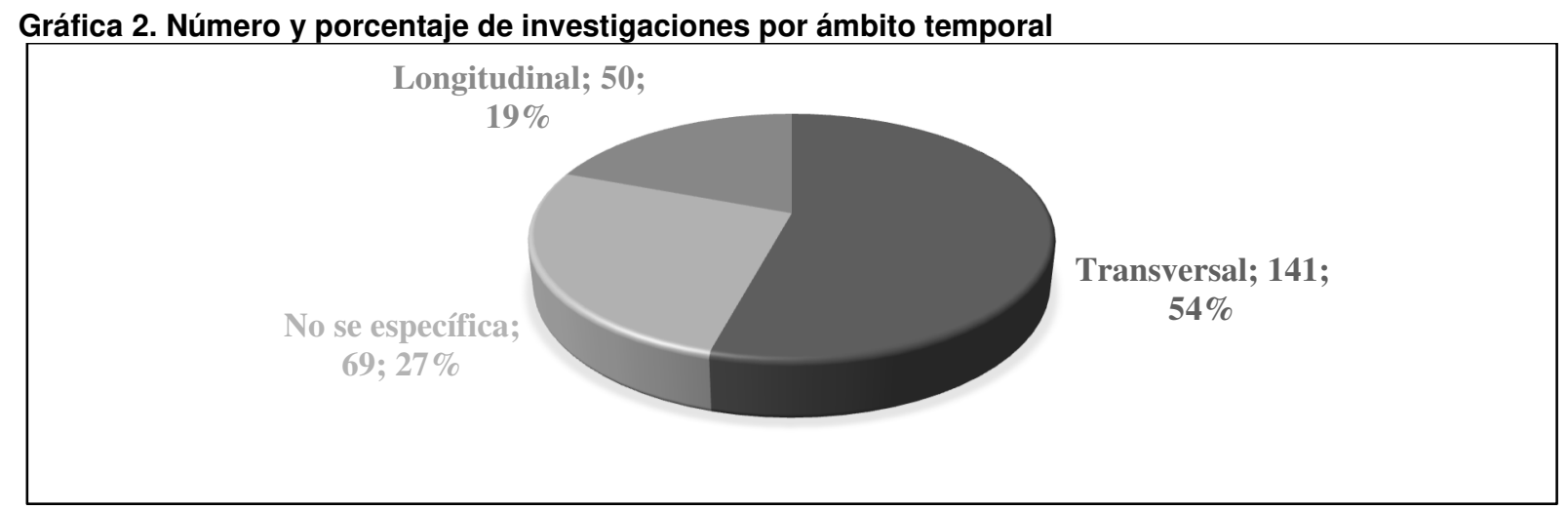

Fuente: Elaboración propia

En cuanto al ámbito geográfico, en la tabla 5 se presenta la relación de los países que son tratados por las diferentes investigaciones, así mismo, se muestra para cada línea la delimitación jurisdiccional a la que se refiere. Se puede observar que una buena parte de los trabajos asume una óptica nacional, esto es como se indicó antes del estado en general, seguido de un grupo de investigaciones enfocadas en lo local, es decir, referente a las municipalidades, gobernaciones o estado federales, específicamente, Brasil aporta la mayoría de los artículos en este aspecto. Por último, se constata el escaso desarrollo de exploraciones científicas continentales.

Tabla 5. Artículos por país y alcance geográfico de la investigación

\begin{tabular}{l|r|r|r|r|r}
\hline \multicolumn{1}{r|}{ Alcance geográfico } & Continental & Local & Nacional & Total & Participación \\
País(es) & & 1 & 5 & $\mathbf{6}$ & $\mathbf{2 , 3 \%}$ \\
\hline Argentina & 2 & & & $\mathbf{2}$ & $\mathbf{0 , 8 \%}$ \\
Argentina, Brasil, Paraguay y Uruguay & 1 & & & $\mathbf{1}$ & $\mathbf{0 , 4 \%}$ \\
Argentina, Chile y Paraguay & 1 & & & $\mathbf{1}$ & $\mathbf{0 , 4 \%}$ \\
Bolivia, Colombia, Ecuador, Perú y Venezuela & & 101 & 67 & $\mathbf{1 6 8}$ & $\mathbf{6 4 , 6 \%}$ \\
Brasil & & 1 & 1 & $\mathbf{2}$ & $\mathbf{0 , 8 \%}$ \\
Chile & & &
\end{tabular}




\begin{tabular}{|c|c|c|c|c|c|}
\hline $\begin{array}{ll} & \text { Alcance geográfico } \\
\text { País(es) } & \\
\end{array}$ & Continental & Local & Nacional & Total & Participación \\
\hline Colombia & & 8 & 44 & 52 & $20 \%$ \\
\hline Colombia y Chile & 1 & & & 1 & $0,4 \%$ \\
\hline Colombia y Perú & 1 & & & 1 & $0,4 \%$ \\
\hline Costa Rica & & & 1 & 1 & $0,4 \%$ \\
\hline Cuba & & 1 & 2 & 3 & $1,2 \%$ \\
\hline Ecuador & & 3 & 2 & 5 & $1,9 \%$ \\
\hline México & & 3 & 5 & 8 & $3,1 \%$ \\
\hline Perú & & 1 & 6 & 7 & $2,7 \%$ \\
\hline Todos los países de la región & 1 & & & 1 & $0,4 \%$ \\
\hline Venezuela & & & 1 & 1 & $0,4 \%$ \\
\hline Total & 7 & 111 & 142 & 260 & \\
\hline Participación & $3 \%$ & $43 \%$ & $55 \%$ & & $100 \%$ \\
\hline
\end{tabular}

Fuente: Elaboración propia

El mayor enfoque en la dimensión nacional de la contabilidad gubernamental se aprecia igualmente en la tabla 6; en el ámbito organizacional una significativa cantidad de los trabajos trata como eje del análisis al sector público en general, a los que se podría adicionar los textos que indican su referencia a entidades del gobierno central. Por otra parte, se encuentran las investigaciones que versan sobre entidades del ámbito local y otro grupo de organizaciones de naturaleza particular como las entidades de control y fiscalización, las universidades, los hospitales y las empresas estatales.

Tabla 6. Artículos discriminados por el ámbito organizacional analizado

\begin{tabular}{l|r|r}
\hline \multicolumn{1}{c|}{ Ámbito Organizacional } & Número de artículos & Participación \\
\hline Sector público en general & 106 & $41 \%$ \\
Municipios & 76 & $29 \%$ \\
Departamento- Estado federal & 28 & $11 \%$ \\
Universidades públicas & 17 & $7 \%$ \\
Entidades de control y fiscalización & 14 & $5 \%$ \\
Gobierno central & 9 & $3 \%$ \\
Hospitales públicos & 6 & $2 \%$ \\
Empresas estatales & 4 & $2 \%$ \\
\hline Total & $\mathbf{2 6 0}$ & $\mathbf{1 0 0 \%}$ \\
\hline
\end{tabular}

Fuente: Elaboración propia

\subsection{Perspectivas para avanzar}

En esta revisión se han observado, por un lado, aportes significativos de la literatura relacionada con contabilidad gubernamental, especialmente, la discusión de asuntos normativos sobre las prácticas contables y presupuestales y su convergencia con estándares internacionales, y por otro, oportunidades para futuras investigaciones. Por ejemplo, respecto a los trabajos que han sido desarrollados tomando un ámbito geográfico continental, se puede interpretar que el interés por esta perspectiva surge de procesos de integración económica que demandarían armonizaciones de la regulación contable gubernamental, como lo exponen los estudios sobre el Mercosur y la CAN (López y Caba, 2003; Caba y Caba, 2005), y como a una considerable distancia lo demuestra el proceso de la Unión Europea con la propuesta de las European Public Sector Accounting Standards (EPSAS). Este es un aspecto clave en las perspectivas para avanzar en la producción científica en los próximos años

En este sentido, las investigaciones podrían enfocarse también, en profundizar el conocimiento de las prácticas de control y contabilidad asociadas a organizaciones muy importantes en el sector público como las universidades, los hospitales y las empresas estatales. Estas instancias cumplen con funciones relevantes del estado latinoamericano respecto de derechos como la educación, la salud y la gestión de recursos energéticos, saneamiento básico e infraestructura civil y de comunicaciones, áreas donde se cuenta con activos públicos muy específicos en términos de su reconocimiento y valoración, por ejemplo, bienes comunitarios, históricos y culturales, carreteras, viaductos, entre otros.

En cuanto al análisis por temáticas, se identifica puntualmente que, las áreas disciplinares más trabajadas en las investigaciones son las de contabilidad financiera, gestión e información presupuestal y 
control fiscal del aparato gubernamental. Con unas participaciones menores se encuentra lo relacionado a la contabilidad de costos y otros temas como e-government, educación, investigación e historia.

Esto se hace aún más notable cuando se analiza cada uno de los temas que se identificaron en estas áreas, cuya participación en el total se señala en la tabla 7. En los aspectos de contabilidad financiera resalta la investigación realizada sobre la normalización y la armonización de prácticas, por ejemplo, en el registro de las depreciaciones y las valorizaciones de activos fijos, también, las tendencias de convergencia con las IPSAS. No obstante, es notable lo mucho que hay que profundizar en el estudio del reconocimiento de los ingresos y los activos intangibles, históricos y culturales (Lima, Silva, Borges y Matias, 2011; Campos, Santos y Lima, 2016; Gutiérrez y Díaz, 2017; Gómez, Hinojosa y Mascle-Allemand, 2018), y la utilidad y la consolidación de la información contable pública (Sousa, Vasconcelos, Caneca y Niyama, 2013).

Tabla 7. Artículos discriminados por temas y áreas

\begin{tabular}{|c|c|c|}
\hline 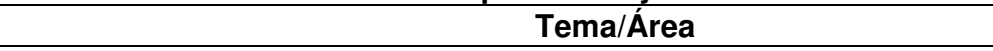 & Artículos & Participación \\
\hline Regulación y normatividad & 25 & $9,6 \%$ \\
\hline Normalización y armonización de prácticas contables & 23 & $8,8 \%$ \\
\hline Convergencia con IPSAS & 21 & $8,1 \%$ \\
\hline Aplicación de conceptos y prácticas contables privadas en lo público & 7 & $2,7 \%$ \\
\hline Bienes de uso público & 6 & $2,3 \%$ \\
\hline Transparencia - disclosure y revelaciones & 4 & $1,5 \%$ \\
\hline Utilidad de la información contable pública & 4 & $1,5 \%$ \\
\hline Caja-devengo & 3 & $1,2 \%$ \\
\hline Consolidación contable & 3 & $1,2 \%$ \\
\hline Contabilidad financiera & 96 & $36,9 \%$ \\
\hline Ejecución del presupuesto - gastos públicos & 21 & $8,1 \%$ \\
\hline Transparencia y revelaciones & 14 & $5,4 \%$ \\
\hline Deuda pública & 12 & $4,6 \%$ \\
\hline Gestión de conocimiento, talento humano y gastos de personal & 6 & $2,3 \%$ \\
\hline Servicios de salud & 3 & $1,2 \%$ \\
\hline Gestión e información presupuestal & 56 & $21,5 \%$ \\
\hline Control interno & 12 & $4,6 \%$ \\
\hline Manipulación y corrupción & 11 & $4,2 \%$ \\
\hline Control fiscal & 10 & $3,8 \%$ \\
\hline Regulación y proceso auditor & 9 & $3,5 \%$ \\
\hline Responsabilidad social y rendición de cuentas & 9 & $3,5 \%$ \\
\hline Control en el gobierno & 51 & $19,6 \%$ \\
\hline Sistemas de costos & 17 & $6,5 \%$ \\
\hline Control de gestión & 5 & $1,9 \%$ \\
\hline Balanced scorecard & 4 & $1,5 \%$ \\
\hline Costeo basado en actividades & 3 & $1,2 \%$ \\
\hline Contabilidad de costos y gestión & 29 & $11,2 \%$ \\
\hline E-government & 9 & $3,5 \%$ \\
\hline Educación & 7 & $2,7 \%$ \\
\hline Historia & 7 & $2,7 \%$ \\
\hline Investigación & 5 & $1,9 \%$ \\
\hline Otros temas & 28 & $10,8 \%$ \\
\hline Total & 260 & $100 \%$ \\
\hline
\end{tabular}

Fuente: Elaboración propia

Así mismo, son de resaltar las investigaciones que buscan comprender la naturaleza y los efectos de estos cambios normativos particulares, y en términos más generales la evolución de los sistemas contables gubernamentales de un determinado país o un conjunto de ellos. Varios trabajos, por ejemplo, aplican conceptos propios del Modelo de Contingencias para explicar las innovaciones en una jurisdicción latinoamericana a partir de restricciones, estímulos y variables estructurales y contextuales de tipo socioeconómico (Caba, López y Ortiz, 2009; Araya, Caba y López, 2011; Gómez y Montesinos, 2012).

Estos instrumentos conceptuales son muy adecuados para tratar de entender un aspecto fundamental: cómo es la dinámica de interrelación entre diferentes doctrinas, ideologías y sistemas políticos y económicos (socialismo del siglo XXI y neoliberalismo, por ejemplo), y la manera como los estados comunican a los ciudadanos la formulación y los resultados de sus políticas públicas por intermedio de la contabilidad (Cohen, Manes, Caperchione y Brusca, 2019). Esto requiere ampliar en la región, como se ha sugerido a nivel global (Jacobs, 2016; Bergmann, Fuchs y Schuler, 2019) la base teórica de las investigaciones sobre contabilidad gubernamental, de manera que aparte de las aproximaciones funcionalistas de la NPM, la teoría de la agencia y el enfoque del accountability, se profundice el empleo de 
esquemas interdisciplinares como las teorías críticas, la governmentality y las diferentes tendencias neoinstitucionalistas (Ocampo, 2018; Neves y Gómez, 2020).

Por otra parte, en el tópico de la gestión presupuestal se ha avanzado en la investigación sobre la ejecución eficiente de los recursos, la perspectiva del gasto en diferentes asuntos, incluso en la transparencia y la revelación de información relacionada a estos procesos, sin embargo, hay potencialidad de contribuir con más estudios en factores como la gestión de la deuda pública, un tópico que sugiere directamente la necesidad de un mayor comprensión de la interrelación entre contabilidad gubernamental y contabilidad nacional (Brusca, 2010); así mismo, investigaciones sobre la caracterización del talento humano asociado a las actividades contables en el estado, aspecto primordial para la optimización de la toma de decisiones en los gobiernos a diferente escala, la generación de balances sociales y otros reportes destinados a los trabajadores oficiales, esto incluso desde una perspectiva de género (Frey, Marcuzzo y Oliveira, 2008; Costa, Souza, Baihe y Filho, 2018).

De manera semejante, como lo han señalado recientemente Hay y Cordery (2018), el control a nivel gubernamental se presenta como una función compleja y poco estudiada en comparación con otras áreas, en este caso también en América Latina. La escasa investigación en aspectos como los ciclos políticos y la manipulación y corrupción en el ámbito estatal (Vicente y Nascimiento, 2012; Laurinho, Dias y Mattos, 2017) o más puntualmente, la demanda de una mayor responsabilidad social y procesos de rendición de cuentas representa una oportunidad desde la academia para contribuir efectivamente con la solución de problemáticas sociales con un alto impacto social en el crecimiento, la justicia y la equidad en la región (Bautista, 2010; Silva Neto, Silva y Goncalves, 2015; Couto y Frey, 2017).

Lo mismo aplica para la contabilidad de costos y gestión aplicada al sector público, si bien se evidencia un interés por reflexionar y aplicar sistemas de costos en las administraciones públicas, hay bastante por recorrer en temas como el control de gestión y, por ejemplo, un aspecto fundamental que no se halló en ninguna investigación la indagación por el reconocimiento y la revelación de los costos y los pasivos sociales y ambientales asociados al desenvolvimiento de la actividad del estado y sus entidades de gobierno, un asunto clave hoy día, especialmente, a nivel de las municipalidades (Quian, Burritt y Monroe, 2018).

En cuanto a otros temas, una perspectiva clave para avanzar es la comprensión de la historia de la contabilidad gubernamental, un aspecto que no es menor ya que se refiere al conocimiento de la evolución institucional que facilita la formulación de propuestas contextualizadas de cambio normativo, técnico y educativo y perfila las posibilidades futuras del área en la región (Rico, 2010; Rodrigues y Sangster, 2013; Lopes y Hanley, 2014). De igual manera es de subrayarse la importancia de estudios sobre la formación y la educación en el tema, donde hay un amplio campo de estudio que explorar, como recientemente los ha reiterado IFAC, a través de su Board de estándares de educación (IAESB, 2019). Esto aplica, igualmente, para las herramientas tecnológicas como el e-government, que, aunque se promocionan bastante en los contratos gubernamentales, son aún incipientes en las investigaciones académicas.

\section{Conclusiones}

Los cambios en la regulación y las prácticas de contabilidad gubernamental en América Latina han reflejado una intensa búsqueda por lograr procesos de modernización de las administraciones públicas y los estados nacionales. Como consecuencia de esto, se ha propiciado una importante inquietud académica por la explicación y la comprensión de dichos fenómenos sociales, aunque no siempre teniendo en cuenta el contexto político, económico e institucional de la región y sus comunidades.

Por tanto, una investigación contable en el área con una definida proyección social que contribuya a interpretar y orientar estas temáticas es primordial y puede ser una poderosa herramienta para lograr mejores diseños institucionales y organizacionales, políticas públicas más racionales y pertinentes en la gestión de la administración pública y, por ende, responsables y eficientes a la hora de gestionar los bienes públicos.

Con esta orientación, en el presente trabajo se revisaron 260 artículos de 56 revistas académicas en 11 países entre el año 2000 y el 2018. A partir de este análisis en general, se identificaron tendencias temáticas, tipos y metodologías de investigación, alcances geográficos y ámbitos temporales y organizacionales. Mas particularmente, de acuerdo con el objetivo propuesto se establecieron algunas perspectivas para avanzar en el fortalecimiento de la investigación en el área de la contabilidad en Latinoamérica.

En el estudio se ha evidenciado un avance gradual en la producción de literatura especializada en múltiples aspectos, particularmente con una notable participación de la investigación brasilera. Como se aprecia en los siguientes aspectos: i) más del $62 \%$ de los artículos hallados son publicados en revistas de este país, ii) la revistas con el mayor número de escritos es Ambiente Contábil con 20 documentos; y iii) los 5 autores con mayor producción son brasileros (Diana Vaz de Lima, Maurício Côrrea da Silva, Orion Augusto Platt Neto, Aneide Oliveira Araújo y Flávio da Cruz).

De otra parte, se puede apreciar que Colombia con 22,3\% sigue a Brasil en cuanto al número de artículos publicados. La Revista Internacional Legis de Contabilidad \& Auditoría y la revista Contaduría Universidad de Antioquia son las más representativas en este país. Se resalta además que, sobre naciones como Bolivia, Paraguay, Uruguay y regiones como Centroamérica y el Caribe, se encontraron pocas 
investigaciones relacionadas o incluso no se halló información. Los documentos fueron escritos por un notable número de 475 investigadores, que encuentran preferencia por escribir documentos en conjunto, más exactamente en grupos de 2 y 3 personas. Excluyendo la participación de Brasil, se halló una representativa cantidad de autores colombianos y peruanos, e incluso, españoles y portugueses.

En concordancia con la literatura previas, dentro de los resultados también se encuentra que predominan las investigaciones que utilizan la metodología de investigación cualitativa, empleando primordialmente, métodos como los análisis documentales y las reflexiones conceptuales. Respecto a las fuentes primarias de los trabajos, se encontró una participación relevante de las normas y legislaciones seguido de estados financieros y cuestionarios-entrevistas-listas de chequeo. El ámbito temporal más utilizado fue de corte transversal con intervalos de tiempo muy cortos y la menor proporción la tienen las evaluaciones de tipo longitudinal. Finalmente, respecto del ámbito geográfico, la mayoría son nacionales seguido por los locales y pocos continentales

Surge como una necesidad clave, la formulación de una mayor cantidad de estudios empíricos formalizados mediante planteamientos estadísticos y econométricos, a partir de los cuales se pueda lograr una comprensión esquemática de las prácticas de contabilidad gubernamental. Así mismo, es relevante que se profundice en tópicos como la utilidad de la información financiera (reconocimiento y valoración de bienes públicos e intangibles) y no financiera (aspectos sociales y ambientales), considerando tendencias temáticas como la lucha contra la corrupción, el entendimiento de las prácticas de auditoría, los procesos de los entes de fiscalización y en temas alternativos como el e-government, la educación y la historia. Esto utilizando ámbitos teóricos, temporales y geográficos más amplios, así como análisis focalizados en instituciones públicas como municipalidades, universidades, hospitales y empresas del estado.

Finalmente, para futuros trabajos, se propone ampliar las fuentes de búsqueda, contemplando, por ejemplo, revistas de administración pública y documentos institucionales y publicaciones seriadas de organismos internacionales; esto con la intención, por un lado, de tener una visión más amplia sobre el campo de estudio y por otro propiciar investigaciones académicas más concretas con propuestas e innovaciones teóricas y técnicas dirigidas a fortalecer gobiernos y ciudadanías más éticas y democráticas.

\section{Referencias}

Abu Bakar, N., \& Saleh, Z. (2011). Incentives for disclosure of accounting information in public sector: a literature survey. International Research Journal of Finance and Economics, 75, 24-38.

Amaral, N., Bolfe, C., \& Vicente, E. (2014). Estudos sobre o regime de competência no setor público brasileiro: os desencontros da discussão acadêmica. Revista Catarinense da Ciência Contábil - CRCSC. 13 (40), 20-36. DOI: http://dx.doi.org/10.16930/2237-7662/rccc.v13n40p20-36

Araya, C., Caba, C. \& López, A. (2011). La innovación en los sistemas de información financiera gubernamental en la región centroamericana: evidencias desde Costa Rica. Innovar, 21(41), 111-123.

Azevedo, R., \& Lino, A. (2018). O distanciamento entre as normas de auditoria e as práticas nos Tribunais de Contas. Sociedade, Contabilidade e Gestão, 13 (2), 9-27.

Banco Mundial. (2015). Contabilidad gubernamental e información financiera en América Latina. Informe No: 101007-CL. Práctica Global de Buen Gobierno, 1-34.

Bautista, J. (2010). Lo público para la contabilidad y la contabilidad para lo público: caminos de investigación y alternativas de desarrollo contable. Revista Activos, 14, 111-130.

Bergman, A., Fuchs, S., \& Shuler, C. (2019). A theoretical basis por public sector accrual accounting research: current state and perspectives. Public Money \& Management, 39 (8), 560-570. DOI: https://doi.org/10.1080/09540962.2019.1654319

Borges, T., \& Matias, M. (2011). Contabilidade gerencial no setor público: o caso de Minas Gerais. Contabilidade Vista \& Revista. 22 (3), 73-98.

Brusca, I. (2010). Treinta años de investigación en contabilidad y gestión pública en España. Revista de Contabilidad, 13 (2), 175-209. DOI: https://doi.org/10.1016/S1138-4891(10)70016-9

Brusca, I., Gómez, M., \& Montesinos, V. (2016). Public financial management reforms: the role of IPSAS in Latin-America. Public Administration and Development, 36 (1), 51-64. DOI: https://doi.org/10.1002/pad.1747 
Caba, C., \& Caba, E. (2005). La armonización de la información financiera pública en los países de la CAN. Revista Internacional Legis de Contabilidad y Auditoría, 23, 141-180.

Caba, C., López, A., \& Ortiz, D. (2009). Governmental financial information reforms and changes in the political system: the Argentina, Chile and Paraguay experience. Public Administration and Development, 29(5), 429-440.

Campos, L., Santos, V., \& Lima, D. (2016). Ativos culturais: uma análise do tratamento contábil em cidades históricas do estado de Goiás. Revista Universo Contábil, 12 (3), 34 - 44.

Castaño, C. (2017). Reflexiones sobre la investigación contable en Colombia. Panorama Económico, 24, 163174.

Cavanagh, J., \& Fernández, A. (2015). Contabilidad pública y credibilidad fiscal. En: Gestión financiera pública en América Latina. Carlos Pimienta y Mario Pessoa (editores). Washington: Banco Interamericano de Desarrollo - Fondo Monetario Internacional. (191-249).

Cohen, S., Manes, F., Caperchione, E., y Brusca, I. (2019). Local government administration system and local government accounting information needs: is there a mismatch? International Review of Administrative Science, 85(4), 708-725. DOI: https://doi.org/10.1177/0020852317748732

Costa, F., Souza, F., Baihe, M., \& Santos Filho, S. (2018). Perfil do professional contábil do setor público: uma análise das capitais brasileiras e Distrito Federal. Revista de Contabilidade da UFBA, 12 (1), 74-92. DOI: http://dx.doi.org/10.9771/rc-ufba.v12i1.23253

Couto, T., \& Frey, M. (2017) Análise da evidenciação da sustentabilidade pela contabilidade aplicada ao setor público municipal. Revista de Contabilidade da UFBA, 11 (2), 45-62. DOI: http://dx.doi.org/10.9771/rcufba.v11i2.16635

Flórez, I. (2010). El Gobierno Corporativo en el ámbito del sector público: un estudio bibliométrico en las revistas ubicadas en el área de Administración Pública. Revista de la Facultad de Ciencias Económica: Investigación y Reflexión, 25 (1), 161-175. DOI: http://dx.doi.org/10.18359/rfce.743

Frey, M., Marcuzzo, J., \& Oliveira, C. (2008) O Balanço social como ferramenta de transparência para o setor público municipal. Revista Universo Contábil, 4 (2), 75-92. DOI: http://dx.doi.org/10.4270/ruc.20084

Gascó, M. (2005). Exploring the e-government gap in South America. International Journal of Public Administration, 28: 7- 8., 683-701. DOI: https://doi.org/10.1081/PAD-200064235

Goddard, A. (2010). Contemporary public sector accounting research - An international comparison of journal papers. The British Accounting Review, 42(2), 75-87. DOI: https://doi.org/10.1016/j.bar.2010.02.006

Gómez, J., Hinojosa, S., y Mascle-Allemand, A. (2018). Despertando el capital cultural. El rendimiento fiscal de los activos arqueológicos, históricos y culturales. Washington: Banco Interamericano de Desarrollo.

Gómez, M., \& Montesions, J., (2012). Las innovaciones en contabilidad gubernamental: el caso de Colombia. Innovar, 22(45), 17-35.

Gutiérrez, J., \& Díaz, M., (2017). Valoración del sistema vial de la ciudad de Bogotá: Una aproximación bajo el nuevo marco normativo contable. Contaduría Universidad de Antioquia, 71, 233-251.

Gutiérrez, R., \& Católico, D. (2015). E-control en las entidades de la rama ejecutiva del orden nacional en Colombia. Cuadernos de Contabilidad, 16 (42), 553-578. DOI: http://dx.doi.org/10.11144/Javeriana.cc1642.eere

Hauque, S. (2007). La registración de los recursos tributarios en el sector público en la etapa del devengado. Ciencias Económicas (UNL), 5(1), 9-22.

Hay, D., \& Cordery, C. (2018). The value of public sector audit: literature and history. Journal of Accounting Literature, 40, 1-15. DOI: https://doi.org/10.1016/j.acclit.2017.11.001

IAESB - IFAC. (August 2019). Illustrative example: designing learning outcomes for curricula that meet public sector accountancy. Implementation Support Material. 
IFAC \& CIPFA. (2018). International public sector financial accountability index. 2018 Status Report.

Jacobs, K. (2016). Theorising interdisciplinary public sector accounting research. Financial Accountability \& Management, 32(4), 469-488. DOI: https://doi.org/10.1111/faam.12093

Khan, A., \& Mayes, S. (2009). Transition of accrual accounting. Technical Notes and Manuals. International Monetary Fund.

Lara, M., Toledo, I., \& Gómez, L. (2012). La rendición de cuentas por el gobierno electrónico. Caso entidades federativas de México. Cuadernos de Contabilidad, 13 (33), 463-478.

Laurinho, I., Dias, L., \& Mattos, C. (2017). Corrupção e ineficiência em licitações de governos locais e desenvolvimento humano: novas reflexões. Revista de Contabilidade e Organizações, 11 (30), 57-70. DOI: http://dx.doi.org/10.11606/rco.v11i30.134529

Leyton, C., \& Gil, J. (2017). Cuadro de mando integral aplicado a la gestión pública de los municipios. Revista Academia \& Negocios, 3(2), 55-66.

Lima, D., Silva, M., Borges, E., \& Matias, J. (2011). Pesquisa empírica: uma contribuição ao tratamento contábil dos bens de uso comum. Revista Ambiente Contábil. 3 (2), 34 - 44.

Lima, R., \& Lima, D. (2019). Experiência do Brasil na implementação das IPSAS. Revista Comtemporânea de Contabilidade. 16 (38), 166 - 184. DOI: http://dx.doi.org/10.5007/2175-8069.2019v16n38p166

Lopes, L., \& Hanley, A. (2014) Alice no país da contabilidade: a aventura de duas historiadoras econômicas em registros contábeis do Século XIX. Revista Contabilidade \& Finanças, 25 (história da contabilidade), 355-363. DOI: http://dx.doi.org/10.1590/1808-057x201411540

López, Ana. (2018). Delitos contra la eficiencia de la administración pública ecuatoriana. Caso de estudio: Morona Santiago. Apuntes Contables, 22, 143-156. DOI: https://doi.org/10.18601/16577175.n22.09

López, A., \& Caba, C. (2003). El impacto de la aplicación de las IPSAS de la IFAC al Mercosur. Contabilidad y Auditoría, 9 (17), 113-130.

Machado, M. (2017). Mejoramiento de la gestión en el sector público: disminuir el riesgo corrupción a partir de la cultura contable ciudadana. Contaduría Universidad de Antioquia, 71, 31-50.

Macías, H. (2018). Introducción a la investigación contable en Brasil. Revista Activos, 16(30), 155-186.

Muñoz, L., Rodríguez, M., \& Garde, R. (2014). Estudio cienciométrico de la investigación en transparencia informativa, participación ciudadana y prestación de servicios públicos mediante la implementación del egobierno. Revista de Contabilidad, 17 (2), 130-142. DOI: https://doi.org/10.1016/j.rcsar.2014.05.001

Neves, F., y Gómez, M. (2020). Public sector accounting reform in Latin America and epistemic communities: an institutional approach. Revista de Administração Pública, 54(1), 11-31. DOI: http://dx.doi.org/10.1590/0034-761220180157x

Nikitin, M. (2001) The birth of a modern public sector accounting system in France and Britain and the influence of Count Mollien, Accounting History, 6(1), 75-101. DOI: https://doi.org/10.1177/103237320100600106

Ocampo, C., (2018). Un panorama del efecto Foucault en contabilidad y gestión pública. Temáticas, autores y retos de investigación desde la gubernamentalidad. Cuadernos de Contabilidad, 19(47), 60-79. DOI: https://doi.org/10.11144/Javeriana.cc19-47.pefc

OCDE. (2019) La Integridad Pública en América Latina y el Caribe 2018-2019. París: Publicaciones de la OCDE.

Quian, W., Burritt, R., \& Monroe, G. (2018) Environmental management accounting local government: functional and institutional imperatives, Financial Accountability \& Management, 34(2), 148-165. DOI: https://doi.org/10.1111/faam.12151 
Quintanilla, D., \& Díaz, M. (2019). Una revisión conceptual y de aplicación de la contabilidad de gestión en el sector público. Contaduría Universidad de Antioquia, 74, 35-57. DOI: https://doi.org/10.17533/udea.rc.n74a02

Reis, L., Slomski, V., Pereira, C., \& Mello, G. (2007). A pesquisa brasileira em contabilidade do setor público: uma análise após a implementação da lei de responsabilidade fiscal. Revista de Informação Contábil. 1 (1), 89- 101.

Restrepo, M. (2018). Calidad de los hallazgos de auditoría. Analisis de caso de las contralorías territoriales de Colombia. Innovar, 28 (70), 115-128. DOI: https://doi.org/10.15446/innovar.v28n70.74452.

Rico, C. (2010). Confiscación de bienes eclesiásticos en Colombia. La contabilidad de la Agencia General de Bienes Desamortizados (1861-1888). De Computis - Revista Española de Historia de la Contabilidad, 7 (12), 41-83. DOI: http://dx.doi.org/10.26784/issn.1886-1881.v7i12.277

Rico, C., \& Díaz, M. (2017). ¿Convergencia de la regulación contable colombiana para las entidades de gobierno con las International Public Sector Accounting Standards (IPSAS)? Una medición de la armonización formal. Contabilidad y Negocios, 12 (24), 61-83. DOI: https://doi.org/10.18800/contabilidad.201702.004

Rodrigues, L., \& Sangster, A. (2013) The role of the state in the development of accounting in the PortugueseBrazilian Empire, 1750-1822, Accounting History Review, 23(2), 161-184. DOI: https://doi.org/10.1080/21552851.2013.803758

Saavedra, M.L., \& Saavedra, M.E. (2015). La investigación contable en Latinoamérica. Actualidad Contable Faces, 18 (31), 99-121.

Sánchez, J., \& Pincay, D. (2013). La contabilidad pública en América Latina y el devengo en Ecuador. Analítika - Revista de Análisis Estadístico, 6 (2), 19-29.

Silva, A., Abreu, C., \& Couto, D. (2017). Evolução do controle interno no setor público: Um estudo dos novos normativos emitidos entre 2003-2016. Revista De Contabilidade Do Mestrado Em Ciências Contábeis Da UERJ, 22 (2), 20-38. DOI: https://doi.org/10.12979/32362

Silva Neto, A., Silva, J., \& Goncalves, R. (2015). Contabilidade aplicada ao setor público como mecanismo institucional estatal de melhoria da Accountability. Reunir: Revista de Administração, Ciências Contábeis e Sustentabilidade, 5 (3), 93-111. DOI: https://doi.org/10.18696/reunir.v5i3.384

Sodré, R. (2017). Sobre corruptos, corrompidos e culpados: relatos de servidores públicos sobre práticas de corrupção. Revista de Contabilidade e Organizações, 11 (31), 21-30. DOI: https://doi.org/10.11606/rco.v11i31.134465

Sousa, R., Vasconcelos, A., Caneca, R., \& Niyama, J. (2013). O regime de competência no setor público brasileiro: uma pesquisa empírica sobre a utilidade da informação contábil. Revista Contabilidade \& Finanças, 24 (63), 219-230. DOI: http://dx.doi.org/10.1590/S1519-70772013000300005.

Souza, F., Silva, M., \& Araújo, A. (2013). Uma análise da produção científica da área de contabilidade governamental nos periódicos que utilizam o SEER e o SciELO. Revista de Contabilidade da UFBA, 7 (2), 22-37.

Sunder, S. (1997). Theory of accounting and control. Cincinnati: South-Western College Pub.

Tamez, S., \& Montesinos, V. (2011). La auditoría como medio de fiscalización de las cuentas públicas mexicanas. Innovaciones de Negocios, 8 (15), 137-174.

Trigo, M., \& Álvarez, V. (2017). Gestión pública, gobierno abierto y fortalecimiento de la democracia en América Latina. En: Desde el gobierno abierto al estado abierto en América Latina y el Caribe. Alejandra Naser, Álvaro Ramírez y Daniela Rosales (editores). Santiago: Comisión Económica para América Latina y El Caribe. (33-51).

Vicente, E., \& Nascimento, L. (2012). A efetividade dos ciclos políticos nos municípios brasileiros: Um enfoque contábil. Revista de Contabilidade e Organizações, 6(14), 106-126. https://doi.org/10.11606/rco.v6i14.45402 
Anexo A. Número de artículos sobre contabilidad gubernamental por país - revista

\begin{tabular}{|c|c|c|c|c|}
\hline Título de la Revista/País & $\begin{array}{c}\text { Año de } \\
\text { constitución }\end{array}$ & $\begin{array}{l}\text { Primer } \\
\text { año de } \\
\text { revisión }\end{array}$ & $\begin{array}{l}\text { Número } \\
\text { de } \\
\text { artículos }\end{array}$ & $\begin{array}{l}\text { Porcentaje } \\
\text { de } \\
\text { participación }\end{array}$ \\
\hline Ciencias Económicas (UNL) & 2005 & 2005 & 1 & $0,4 \%$ \\
\hline Contabilidad y Auditoría & 1995 & 2000 & 2 & $0,8 \%$ \\
\hline DAAPGE (Documentos y Aportes en Administración Pública y Gestión Estatal) & 2001 & 2001 & 4 & $1,5 \%$ \\
\hline Argentina & & & 7 & $2,7 \%$ \\
\hline BAR - Brazilian Administration Review & 2004 & 2004 & 1 & $0,4 \%$ \\
\hline BASE - Revista de Administração e Contabilidade da Unisinos & 2004 & 2004 & 2 & $0,8 \%$ \\
\hline CAP - Accounting and Management & 2006 & 2006 & 2 & $0,8 \%$ \\
\hline Contabilidade Vista \& Revista & 1989 & 2000 & 9 & $3,5 \%$ \\
\hline Enfoque: Reflexão Contábil & 1991 & 2005 & 3 & $1,2 \%$ \\
\hline RACE - Revista de Administração, Contabilidade e Economia & 2005 & 2005 & 7 & $2,7 \%$ \\
\hline RACEF - Revista de Administração, Contabilidade e Economia da FUNDACE & 2010 & 2010 & 2 & $0,8 \%$ \\
\hline RBC: Revista Brasileira de Contabilidade & 1971 & 2002 & 13 & $5,0 \%$ \\
\hline Registro Contábil - RECONT & 2010 & 2010 & 3 & $1,2 \%$ \\
\hline Reunir: Revista de Administração, Ciências Contábeis e Sustentabilidade & 2011 & 2011 & 5 & $1,9 \%$ \\
\hline Revista Ambiente Contábil & 2009 & 2009 & 20 & $7,7 \%$ \\
\hline Revista Catarinense da Ciência Contábil & 2001 & 2001 & 11 & $4,2 \%$ \\
\hline Revista Contabilidade \& Finanças & 1989 & 2001 & 9 & $3,5 \%$ \\
\hline Revista Contemporânea de Contabilidade & 2004 & 2004 & 6 & $2,3 \%$ \\
\hline Revista Controle & 2005 & 2005 & 8 & $3,1 \%$ \\
\hline Revista de Administração de Roraima & 2011 & 2011 & 2 & $0,8 \%$ \\
\hline Revista de Contabilidade da UFBA & 2007 & 2007 & 11 & $4,2 \%$ \\
\hline Revista de Contabilidade do Mestrado em Ciências Contábeis da UERJ & 1995 & 2000 & 7 & $2,7 \%$ \\
\hline Revista de Contabilidade e Organizações & 2007 & 2007 & 13 & $5,0 \%$ \\
\hline Revista de Educação e Pesquisa em Contabilidade & 2007 & 2007 & 2 & $0,8 \%$ \\
\hline Revista de Gestão, Finanças e Contabilidade & 2011 & 2011 & 3 & $1,2 \%$ \\
\hline Revista de Informação Contábil & 1989 & 2001 & 9 & $3,5 \%$ \\
\hline Revista Evidenciação Contábil \& Finanças & 2013 & 2013 & 4 & $1,5 \%$ \\
\hline Revista Mineira de Contabilidade & 2000 & 2000 & 2 & $0,8 \%$ \\
\hline Revista Universo Contábil & 2005 & 2005 & 6 & $2,3 \%$ \\
\hline Sociedade, Contabilidade e Gestão & 2006 & 2006 & 2 & $0,8 \%$ \\
\hline Brasil & & & 162 & $62,3 \%$ \\
\hline Capic Review & 2003 & 2003 & 1 & $0,4 \%$ \\
\hline Revista Academia \& Negocios (RAN) & 2015 & 2015 & 1 & $0,4 \%$ \\
\hline Chile & & & 2 & $0,8 \%$ \\
\hline Apuntes Contables & 2002 & 2002 & 6 & $2,3 \%$ \\
\hline Contaduría Universidad de Antioquia & 1982 & 2000 & 11 & $4,2 \%$ \\
\hline Criterio Libre & 2002 & 2010 & 2 & $0,8 \%$ \\
\hline Cuadernos de Contabilidad & 1995 & 2008 & 9 & $3,5 \%$ \\
\hline Estudios Gerenciales & 1998 & 2000 & 2 & $0,8 \%$ \\
\hline Innovar & 1991 & 2000 & 4 & $1,5 \%$ \\
\hline Revista Activos & 1994 & 2007 & 3 & $1,2 \%$ \\
\hline Revista Colombiana de Contabilidad & 2013 & 2013 & 1 & $0,4 \%$ \\
\hline Revista de la Facultad de Ciencias Económica: Investigación y Reflexión & 1992 & 2010 & 3 & $1,2 \%$ \\
\hline Revista Internacional Legis de Contabilidad \& Auditoría & 2000 & 2000 & 13 & $5,0 \%$ \\
\hline Revista Lúmina & 1996 & 2000 & 4 & $1,5 \%$ \\
\hline Colombia & & & 58 & $22,3 \%$ \\
\hline Revista Cubana de Contabilidad y Finanzas & 2011 & 2011 & 3 & $1,2 \%$ \\
\hline Cuba & & & 3 & $1,2 \%$ \\
\hline Analítika - Revista de Análisis estadístico & 2011 & 2011 & 1 & $0,4 \%$ \\
\hline Ecuador & & & 1 & $0,4 \%$ \\
\hline Decomputis - Revista Española de Historia de la Contabilidad & 2004 & 2004 & 2 & $0,8 \%$ \\
\hline España & & & 2 & $0,8 \%$ \\
\hline Contaduría y Administración & 1956 & 2004 & 1 & $0,4 \%$ \\
\hline Innovaciones de Negocios & 2004 & 2004 & 3 & $1,2 \%$ \\
\hline Quid luris & 2005 & 2005 & 1 & $0,4 \%$ \\
\hline Retos de la Dirección & 2007 & 2015 & 1 & $0,4 \%$ \\
\hline México & & & 6 & $2,3 \%$ \\
\hline Contabilidad y Negocios & 2006 & 2006 & 5 & $1,9 \%$ \\
\hline Quipukamayoc & 1993 & 2000 & 6 & $2,3 \%$ \\
\hline Perú & & & 11 & $4,2 \%$ \\
\hline Accounting History Review & 1990 & 2000 & 1 & $0,4 \%$ \\
\hline International Journal of Public Administration & 1979 & 2000 & 3 & $1,2 \%$ \\
\hline Public Administration and Development & 1981 & 2000 & 2 & $0,8 \%$ \\
\hline Reino Unido & & & 6 & $2,3 \%$ \\
\hline Espacios & 1980 & 2000 & 1 & $0,4 \%$ \\
\hline Revista Venezolana de Gerencia & 1996 & 2000 & 1 & $0,4 \%$ \\
\hline Venezuela & & & 2 & $0,8 \%$ \\
\hline Total & & & 260 & $100 \%$ \\
\hline
\end{tabular}

Fuente: Elaboración propia, a partir de las páginas web de las revistas (2019) 


\section{NOTAS}

\section{AGRADECIMIENTOS}

No se aplica.

\section{CONTRIBUCIONES DE AUTORIA}

Concepción y elaboración del manuscrito: M. A. Díaz, C. O. Rico-Bonilla

Recolección de datos: M. A. Díaz, C. O. Rico-Bonilla

Análisis de datos: M. A. Díaz, C. O. Rico-Bonilla

Discusión de resultados: M. A. Díaz, C. O. Rico-Bonilla

Revisión y aprobación: M. A. Díaz, C. O. Rico-Bonilla

\section{CONJUNTO DE DADOS DE LA INVESTIGACIÓN}

O conjunto de dados que dá suporte aos resultados deste estudo não está disponível publicamente.

\section{FINANCIACIÓN}

No se aplica.

\section{CONSENTIMIENTO DE USO DE IMAGEN}

No se aplica.

\section{APROBACIÓN DEL COMITÉ DE ÉTICA DE INVESTIGACIÓN \\ No se aplica.}

\section{CONFLICTO DE INTERESES}

No se aplica.

\section{LICENCIA DE USO}

Los derechos de autor de los artículos publicados en esta revista pertenecen al autor, con los derechos de primera publicación de la revista. Por aparecer en esta Revista de Acceso Público, los artículos son de uso libre, con atribuciones propias, en aplicaciones educativas, profesionales y de gestión pública. La revista adoptó la licencia Creative Commons Attribution 4.0 International - CC BY NC ND. Esta licencia permite acceder, descargar, copiar, imprimir, compartir, reutilizar y distribuir artículos siempre que se cite la fuente, atribuyéndose los debidos créditos de autoría. En tales casos, no se requiere permiso de los autores o editores. Los autores están autorizados a asumir contratos adicionales por separado, para la distribución no exclusiva de la versión del trabajo publicado en esta revista (por ejemplo, publicación en repositorio institucional o capítulo de un libro).

\section{PUBLISHER}

Universidade Federal de Santa Catarina. Curso de Ciências Contábeis y Programa de Pós-graduação em Contabilidade. Publicación en el Portal de Revistas UFSC. Las ideas expresadas en este artículo son responsabilidad de sus autores y no necesariamente representan la opinión de los editores o de la universidad.

\section{EDITORES}

Carlos Eduardo Facin Lavarda y Suliani Rover

\section{HISTÓRICO}

Recibido en: 23/12/2019 - Revisado por pares en: 02/05/2020 - Reformulado en: 29/05/2020 - Recomendado para publicación en: 10/07/2020 - Publicado en: 30/07/2020 